\title{
Commodity Price Volatility
}

\section{and the Economic Uncertainty of Pandemics}

\author{
Dimitrios Bakas ${ }^{a, c t}$ and Athanasios Triantafyllou ${ }^{b}$ \\ ${ }^{a}$ Nottingham Business School, Nottingham Trent University, UK \\ ${ }^{b}$ Essex Business School, University of Essex, UK \\ cRimini Centre for Economic Analysis (RCEA), Canada
}

\begin{abstract}
We empirically investigate the impact of economic uncertainty related to global pandemics on the volatility of the broad commodity price index as well as on the sub-indexes of crude oil and gold. The results show that uncertainty related to pandemics have a strong negative impact on the volatility of commodity markets and especially on crude oil market, while the effect on gold market is positive but less significant.
\end{abstract}

Keywords: Pandemics, Commodity Markets, Economic Uncertainty, Volatility

JEL Classification: C32, Q02, I10

\footnotetext{
${ }^{\dagger}$ Acknowledgments: We would like to thank an anonymous referee for helpful comments and suggestions. Any remaining errors are the responsibility of the authors. The authors declare that they have no conflict of interest. Corresponding author: Dimitrios Bakas, Department of Economics, Nottingham Business School, Nottingham Trent University, 50 Shakespeare Street, NG1 4FQ, Nottingham, United Kingdom. Tel: +44 (0)115 8484191. E-mail addresses: dimitrios.bakas@ntu.ac.uk (D. Bakas), a.triantafyllou@essex.ac.uk (A. Triantafyllou).
} 


\section{Introduction}

The sharp increase in uncertainty during the current coronavirus disease (COVID-19) pandemic has a massive effect on the real economy and the financial sphere. Typically, rising uncertainty about pandemics is associated with falling aggregate demand and disruption in economic activity. For instance, the world industrial production index (Baumeister and Hamilton, 2019) has fallen by 4.5 percent in the first quarter of 2020 as a result of the recent COVID-19 pandemic episode. A number of recent works has emerged in the literature exploring the economic and market effects of pandemics (Baker et al., 2020a,b; Jordà et al., 2020; Ma et al., 2020; among others). Baker et al. (2020a) show the enormous negative effect of COVID-induced economic uncertainty on US real GDP, while Ma et al. (2020) provide further evidence of a persistent negative impact on real GDP growth for a panel of 210 countries, and of a negative stock market response. Baker et al. (2020b) show that the COVID-19 pandemic has an unpresented positive impact on stock-market volatility when compared with the respective effect of various other infectious diseases. In addition, Jordà et al. (2020) provide evidence that pandemics reduce the real rate of interest in the long-run. Furthermore, a significant body of the recent empirical literature is focusing on the impact of economic uncertainty shocks on the volatility of commodity markets (Bakas and Triantafyllou, 2018; Prokopczuk et al., 2019; Van Robays, 2016; among others). ${ }^{1}$ However, while there is some empirical evidence showing the market effects of pandemic shocks, and a vast empirical literature on the role of various types of uncertainty on commodity volatility, there is no

\footnotetext{
${ }^{1}$ Bakas and Triantafyllou (2018) show that macroeconomic uncertainty has a positive impact on the volatility of agricultural, metals and energy commodities, while Prokopczuk et al. (2019) find a strong co-movement between economic uncertainty and volatility in major commodity markets. Furthermore, Van Robays (2016) shows that higher macroeconomic uncertainty alters the price elasticity of oil supply and demand and hence, for the same demand or supply shock, the reaction of oil prices is stronger. Thus, oil price response will be higher since there will be less adjustment though quantities and more adjustment through changing prices. Therefore, lower price elasticity of demand results to higher oil price volatility. Baumeister and Peersman (2013) provide empirical insights by showing that the drop in the price elasticity of oil demand and supply is the key economic mechanism which explains the negative relationship between oil production volatility and oil price volatility.
} 
work exploring the effect of uncertainty shocks related to global pandemics on commodity markets. In this paper, we fill this gap in the literature, by examining empirically, using a VAR model, the dynamic impact of a pandemic uncertainty shock on the volatility of commodity markets.

Commodity prices are driven by aggregate demand and supply shocks, so, in times of higher probability of an economic disruption (higher uncertainty about a future pandemic), the price elasticity of commodity supply and demand increases, with both supply and demand falling rapidly and steadily over time. For example, in the recent coronavirus pandemic episode, the International Energy Agency (IEA) forecasts a 435 thousand barrels a day drop in global demand for oil, while the reaction of the Organization of the Petroleum Exporting Countries (OPEC) is an analogous cut in oil production. Thus, the equilibrium price in the commodity markets comes via the more elastic price adjustment of supply and demand. As a result, commodity prices adjust to the falling production and demand levels by declining instantly and monotonically (i.e., decreasing commodity price fluctuations) to reflect the anticipated drop in economic activity. A clear evidence of this is that the Standard \& Poor's 'Goldman Sachs Commodity Index' (S\&P GSCI) commodity price index has lost $40.6 \%$ of its value during the first quarter of 2020 , with the oil price index has experienced a loss of $56.3 \%$, while the gold price index has increased by $26.4 \%$. The rapid increase in the gold price and the fall in the oil price in the first quarter of 2020 is a clear indication of rising demand for gold and falling demand for oil during the recent pandemic shock. ${ }^{2}$

\footnotetext{
2 This rapid increase in price and demand for gold during times of extreme market stress is in line with the literature that identify gold as safe haven for investors during turbulent times (Baur and McDermott, 2010).
} 
Our VAR analysis shows that the response of commodity volatility to a pandemic uncertainty shock is negative and remains statistically significant for approximately one year after the initial shock. Our paper is the first to reveal a negative and significant response of commodity volatility to pandemic uncertainty shocks. This provides further empirical insights on the role of pandemics on commodity markets as it implicitly signifies that a pandemic is associated with falling aggregate demand for commodities, hence, decreasing volatility in commodity markets. In simple words, higher uncertainty about a pandemic is transferred to economic agents as less uncertainty about aggregate demand and supply conditions, hence, less uncertainty (or volatility) in commodity prices. Moreover, our analysis is the first to show that, unlike the positive response of equity market volatility during pandemics (Baker et al., 2020b), the response of commodity market volatility is the opposite.

We additionally examine the impact of a pandemic uncertainty shock on oil and gold price volatility. Our findings show that volatility in the oil market reduces substantially after a pandemic uncertainty shock, while the response of gold volatility is positive. The negative response of oil volatility is in line with the findings of Van Robays (2016) and Baumeister and Peersman (2013). Thus, we implicitly show that pandemic uncertainty results to rising elasticity of aggregate demand and supply in the oil market and hence, the equilibrium comes through adjustment of quantities and less through oil price fluctuations, and therefore a lower oil volatility after the occurrence of a pandemic episode. On the other hand, the positive response of gold volatility in the fear of a pandemic, is in line with the safe haven property of gold in recessionary times (Baur and McDermott, 2010). ${ }^{3}$

\footnotetext{
${ }^{3}$ Our findings on the positive effect on the gold market signify that rising volatility in gold markets is essentially demand driven. A stylized fact in commodity markets is that rising demand for a commodity results to a rapid rise in
} 


\section{Data and VAR Models}

\subsection{Data}

We obtain the daily excess returns data of the S\&P GSCI broad commodity index and the subindexes of crude oil and gold from Datastream. The quarterly commodity volatility measure $(R V)$ is computed as the realized variance of the daily excess returns for each index, following Bakas and Triantafyllou (2018). ${ }^{4}$ In addition, we compute the quarterly log returns measure $(L R)$ for each index. The world pandemic uncertainty index (WPUI) is based on the work of Ahir et al. (2019) and measures economic uncertainty related to pandemics and other disease outbreaks across the world as reflected in the Economist Intelligence Unit country reports. The world industrial production index (WIP) is based on the work of Baumeister and Hamilton (2019) and measures the industrial production of the OECD plus 6 other major countries, while the geopolitical risk index $(G P R)$ is based on the work of Caldara and Iacoviello (2018) and measures uncertainty related to geopolitical tensions as reflected in leading international newspapers. ${ }^{5}$ The quarterly dataset covers the period from January 1996 to March 2020 (1996Q1-2020Q1) due to data availability of the WPUI index.

\subsection{VAR Models}

We estimate three 5-factor VAR models for the volatility of commodity markets (broad commodity index, crude oil and gold), in which we include the logarithm of the world industrial production

\footnotetext{
both the commodity price and volatility, where unlike equity markets, prices and volatility in commodity markets are positively associated (Pindyck, 2004).

${ }^{4}$ Previous literature shows evidence that commodity prices are I(1) series (Ghoshray, 2011). We confirm this using the $\mathrm{ADF}$ unit root test on the underlying daily commodity series. In addition, we show that the quarterly $R V$ series are stationary. The results of the unit root tests can be provided upon request.

5 The WPUI index is downloaded from https://worlduncertaintyindex.com/, the WIP index is downloaded from Christiane Baumeister's webpage (https://sites.google.com/site/cjsbaumeister/), while the GPR index is downloaded from Matteo Iacoviello's webpage (https://www.matteoiacoviello.com/gpr.htm).
} 
index $(L W I P)$, the log returns $(L R)$ and the volatility $(R V)$ measures for each commodity index, the logarithm of the geopolitical risk index $(L G P R)$ and the world pandemic uncertainty index (WPUI). ${ }^{6}$ Following Jurado et al. (2015), we use a recursive identification procedure where the uncertainty measures are placed last in the VAR ordering. Hence, the VAR ordering is $\left[\begin{array}{llllll}L W I P_{t} & L R_{t} & R V_{t} & L G P R_{t} & W P U I_{t}\end{array}\right]$, where $L R$ and $R V$ are the measures for each commodity index (broad commodity index, crude oil and gold), respectively. The rest of the variables are common for all VAR models.

\section{Empirical Analysis}

Figure 1 shows the volatility in commodity markets while Figure $\mathbf{2}$ shows the synchronous movement of commodity volatility and the world pandemic uncertainty index.

\section{[Figures 1-2]}

From Figure 1 we observe that the volatility of the broad commodity index and of oil market is significantly higher compared to gold for the whole sample. Moreover, from Figure 2 we can observe that jumps in the pandemic uncertainty index are mainly associated with falling commodity price uncertainty.

\subsection{Main Results}

Here we present the results of our 5-factor VAR models. Figure 3 shows the generalized impulse response functions (IRFs) for the volatility of the broad commodity index, which do not depend

\footnotetext{
${ }^{6}$ We include two lags following the optimal-lag length criterion of Akaike.
} 
on the VAR ordering, to a one-standard deviation increase in the world pandemic uncertainty shock.

\section{[Figure 3]}

According to Figure 3, a positive shock in pandemic uncertainty reduces commodity volatility by approximately $1.9 \%$ one quarter after the shock, with the effect remaining significantly negative for about 4 quarters after the initial shock. In this multivariate VAR setting, we control for aggregate demand and commodity specific demand (via commodity price returns) shocks, hence, we take into account the possible dynamic interactions of pandemic uncertainty with demand shocks. In this way, we implicitly control for the aggregate demand shocks when estimating the impact of pandemic uncertainty on commodity volatility.

Figures 4-5 report the generalized impulse response functions of crude oil and gold price volatility to a one-standard deviation increase in the pandemic uncertainty shock.

\section{[Figures 4-5]}

From Figures 4-5 we observe that a positive pandemic uncertainty shock reduces oil price volatility about 270 basis points one quarter after the shock, with the effect remaining significant for four quarters after the initial shock. On the other hand, a positive pandemic uncertainty shock increases gold price volatility about 30 basis points one quarter after the initial shock while the effect fades away quickly. Our results are the first to show the opposite effect of world pandemic 
uncertainty shocks to gold and oil price volatility. Our evidence reveals that the pandemic uncertainty shock results to rising demand for gold and falling demand for oil, since we find a substantial reduction to oil price volatility and a substantial increase in gold price volatility after the pandemic uncertainty shock. The negative response of oil volatility is in line with the findings of Van Robays (2016) and Baumeister and Peersman (2013), while the positive response of gold volatility is in line with the literature on the safe haven property of gold (Baur and McDermott, 2010).

\subsection{Robustness}

Finally, we estimate alternative VAR models to check the robustness of our main results. In specific, a) we employ a bivariate VAR setting with the different commodity volatility measures and the world pandemic uncertainty index, b) we estimate the orthogonalized IRFs using a Cholesky decomposition based on our VAR ordering, instead of the generalized IRFs, and finally, c) we explore the robustness of both the 5-factor VARs and the bivariate VARs to the recent coronavirus outbreak by excluding the observation of 2020Q1. From Figures 6-8 we can observe that our main results and conclusions are qualitatively the same.

\section{[Figure 6-8]}

Interestingly, when excluding the observation for the recent COVID-19 outbreak (2020Q1) we find that the negative response of oil price volatility to a pandemic uncertainty shock decreases slightly in magnitude. This finding implicitly shows the unprecedented impact of the recent coronavirus pandemic on the global oil market. On the other hand, the positive response of gold 
price volatility remains roughly the same (when we exclude 2020Q1) showing that the impact of the COVID-19 pandemic does not have substantially different effect on the gold market when compared with the effect of the previous pandemic episodes.

\section{Conclusions}

This paper examines the impact of economic uncertainty of pandemics on the volatility of commodity markets. The broad measure of commodity volatility and the volatility in oil market are significantly reduced when uncertainty about pandemics rises, with the effect remaining negative and statistically significant for about a year after the uncertainty shock. In contrast, the effect on the gold market is positive but less significant. The main channel through which pandemic uncertainty shocks reduce commodity price volatility comes via the disruption in global demand in pandemic times. This paper provides a first insight on the impact of pandemics on commodity markets, however as the COVID-19 episode is currently in progress, more empirical research is needed when the pandemic is finally over.

\section{References}

Ahir, H., Bloom, N., and Furceri, D. (2019), The World Uncertainty Index, SIEPR Working Paper No. 19027, Stanford Institute for Economic Policy Research.

Bakas, D., and Triantafyllou, A. (2018). The Impact of Uncertainty Shocks on the Volatility of Commodity Prices, Journal of International Money and Finance, 87, 96-111.

Baker, S.R., Bloom, N., Davis, S.J., and Terry, S.J. (2020a). COVID-Induced Economic Uncertainty, NBER Working Paper No. 26983, National Bureau of Economic Research.

Baker, S.R., Bloom, N., Davis, S.J., Kost, K., Sammon, M., and Viratyosin, T. (2020b). The Unprecedented Stock Market Reaction to COVID-19, Covid Economics: Vetted and Real-Time Papers, 1, 33-42. 
Baumeister, C., and Hamilton, J.D. (2019). Structural Interpretation of Vector Autoregressions with Incomplete Identification: Revisiting the Role of Oil Supply and Demand Shocks, American Economic Review, 109, 1873-1910.

Baumeister, C., and Peersman, G. (2013). The Role of Time-Varying Price Elasticities in Accounting for Volatility Changes in the Crude Oil Market, Journal of Applied Econometrics, 28, 1087-1109.

Baur, D.G., and McDermott, T.K. (2010). Is Gold a Safe Haven? International Evidence, Journal of Banking and Finance, 34, 1886-1898.

Caldara, D., and Iacoviello, M. (2018). Measuring Geopolitical Risk, International Finance Discussion Paper No. 1222, Board of Governors of the Federal Reserve System.

Ghoshray, A. (2011). A Reexamination of Trends in Primary Commodity Prices, Journal of Development Economics, 95, 242-251.

Jordà, Ò., Singh, S.R., and Taylor, A.M. (2020). Longer-Run Economic Consequences of Pandemics, Covid Economics: Vetted and Real-Time Papers, 1, 1-15.

Jurado, K., Ludvigson, S.C., and Ng, S. (2015). Measuring Uncertainty, American Economic Review, 105, $1177-1216$.

Ma, C., Rogers, J. H., and Zhou, S. (2020). Global Economic and Financial Effects of 21st Century Pandemics and Epidemics, Covid Economics: Vetted and Real-Time Papers, 5, 56-78.

Pindyck, R.S. (2004). Volatility and Commodity Price Dynamics, Journal of Futures Markets: Futures, Options, and Other Derivative Products, 24, 1029-1047.

Prokopczuk, M., Stancu, A., and Symeonidis, L. (2019). The Economic Drivers of Commodity Market Volatility, Journal of International Money and Finance, 98, 102063.

Van Robays, I. (2016). Macroeconomic Uncertainty and Oil Price Volatility, Oxford Bulletin of Economics and Statistics, 78, 671-693. 


\section{Figures}

Figure 1. Volatility in Commodity Markets

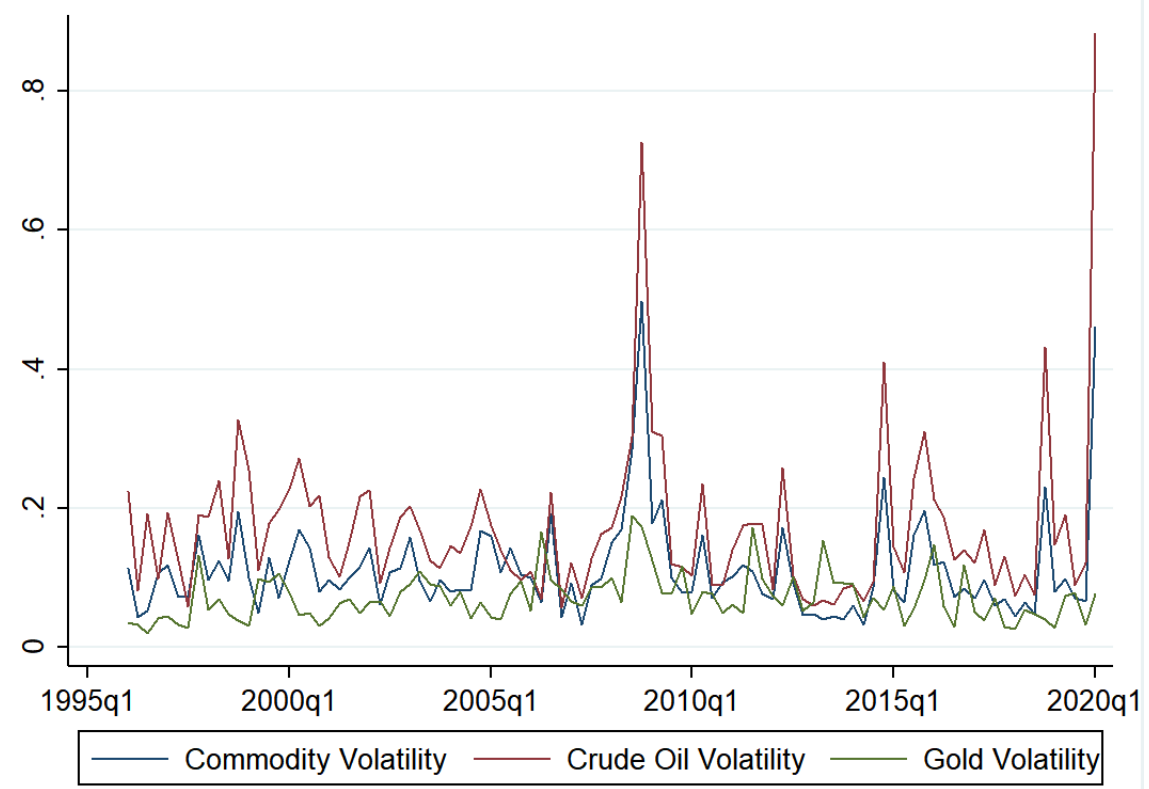

Figure 2. Volatility in Commodity Markets and World Pandemic Uncertainty Index

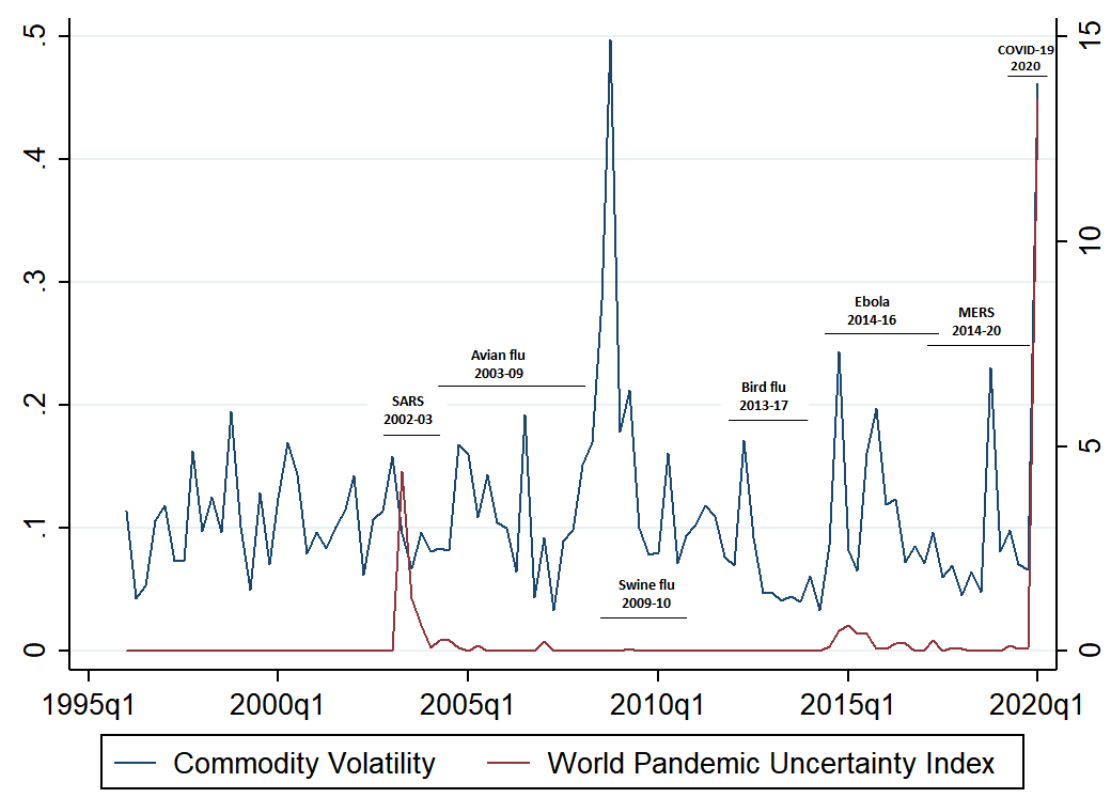




\section{Figure 3. World Pandemic Uncertainty Shock and Commodity Volatility}

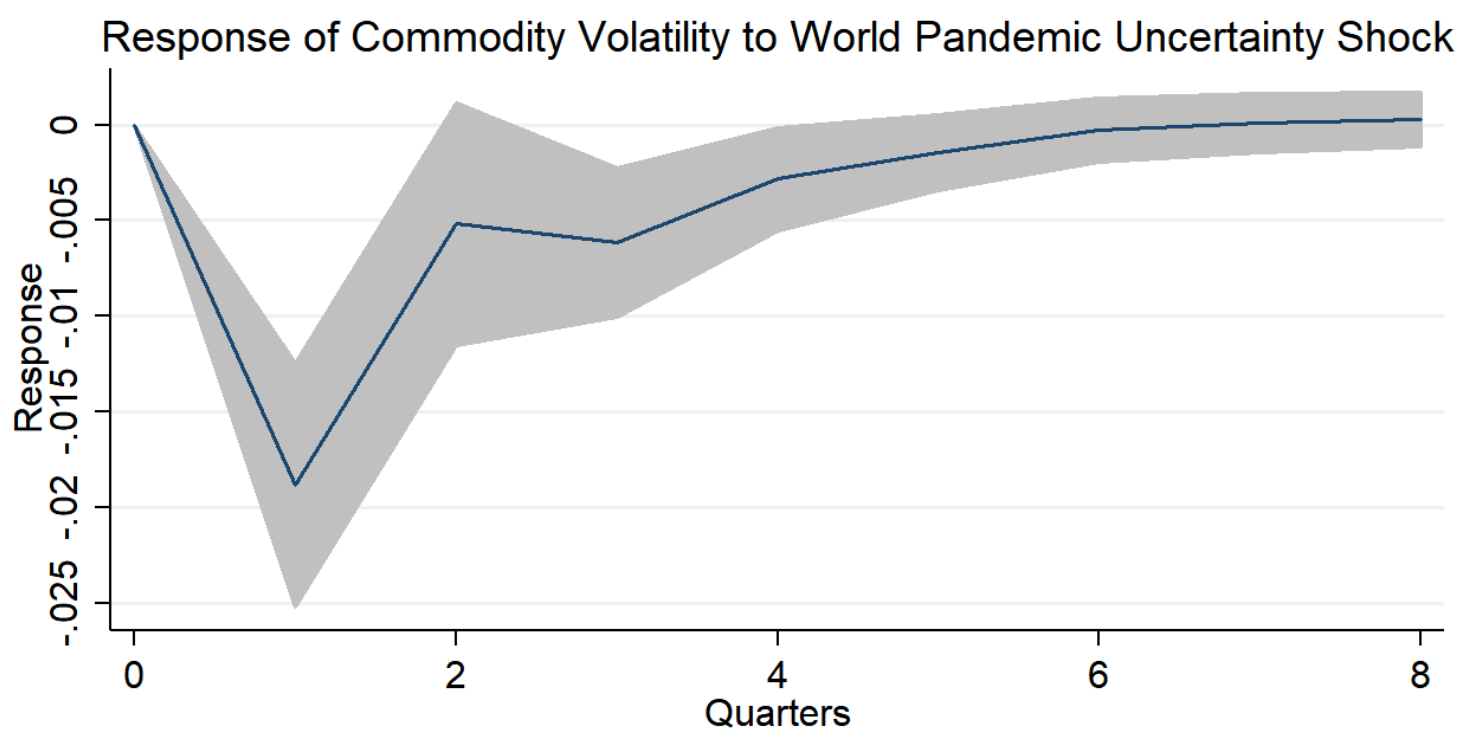

Notes: The grey shaded areas are one-standard error bands. The error bands are constructed via bootstrap with 1000 replications.

\section{Figure 4. World Pandemic Uncertainty Shock and Crude Oil Volatility}

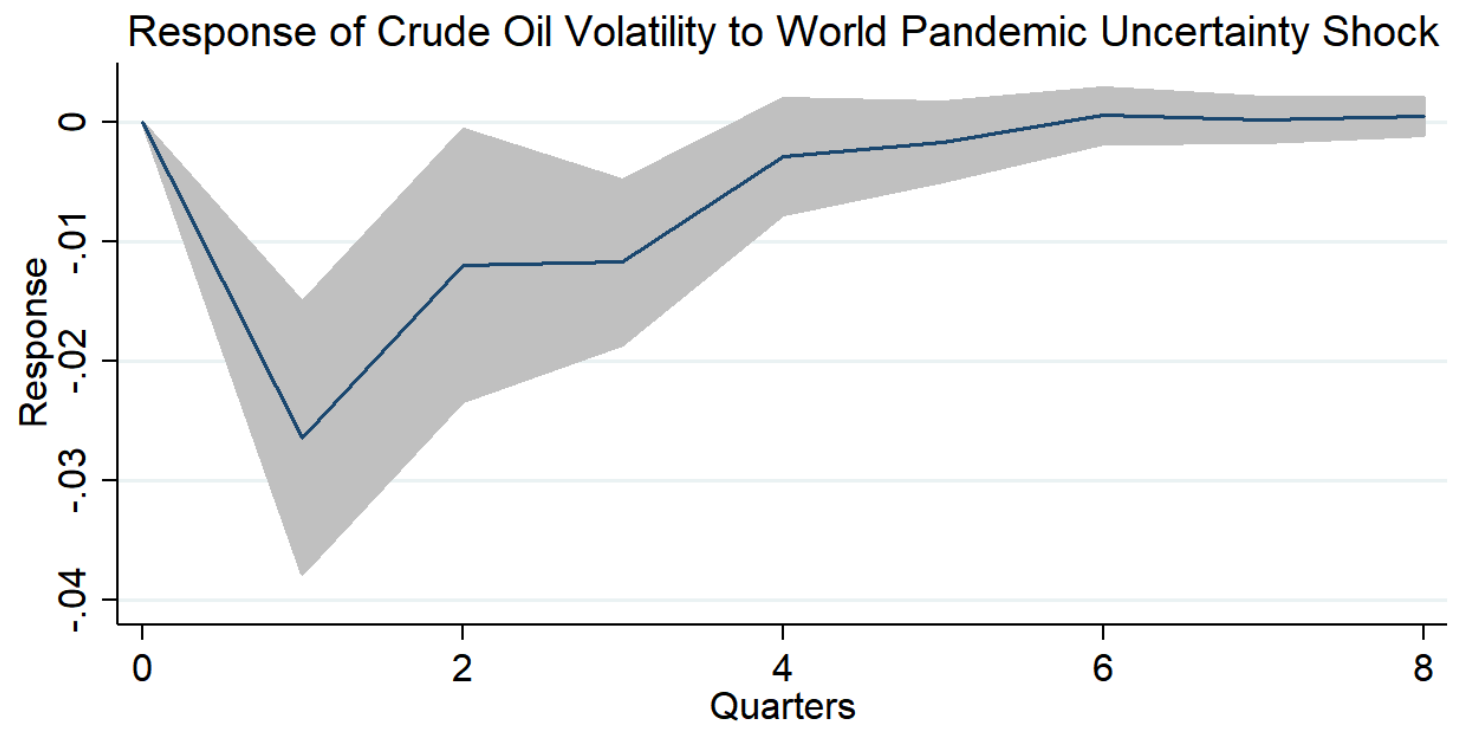

Notes: The grey shaded areas are one-standard error bands. The error bands are constructed via bootstrap with 1000 replications. 


\section{Figure 5. World Pandemic Uncertainty Shock and Gold Volatility}

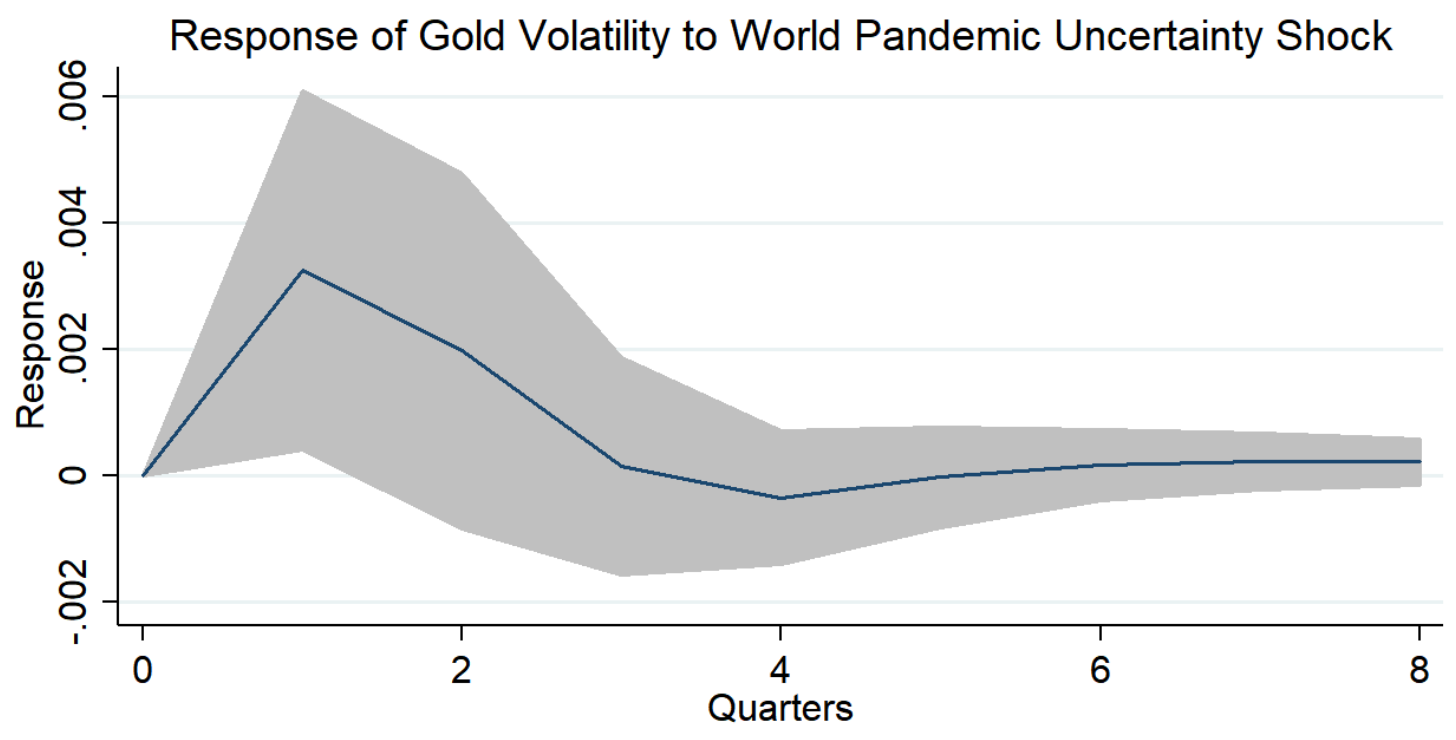

Notes: The grey shaded areas are one-standard error bands. The error bands are constructed via bootstrap with 1000 replications.

\section{Figure 6. World Pandemic Uncertainty Shock and Commodity Volatility (Alternative VARs)}

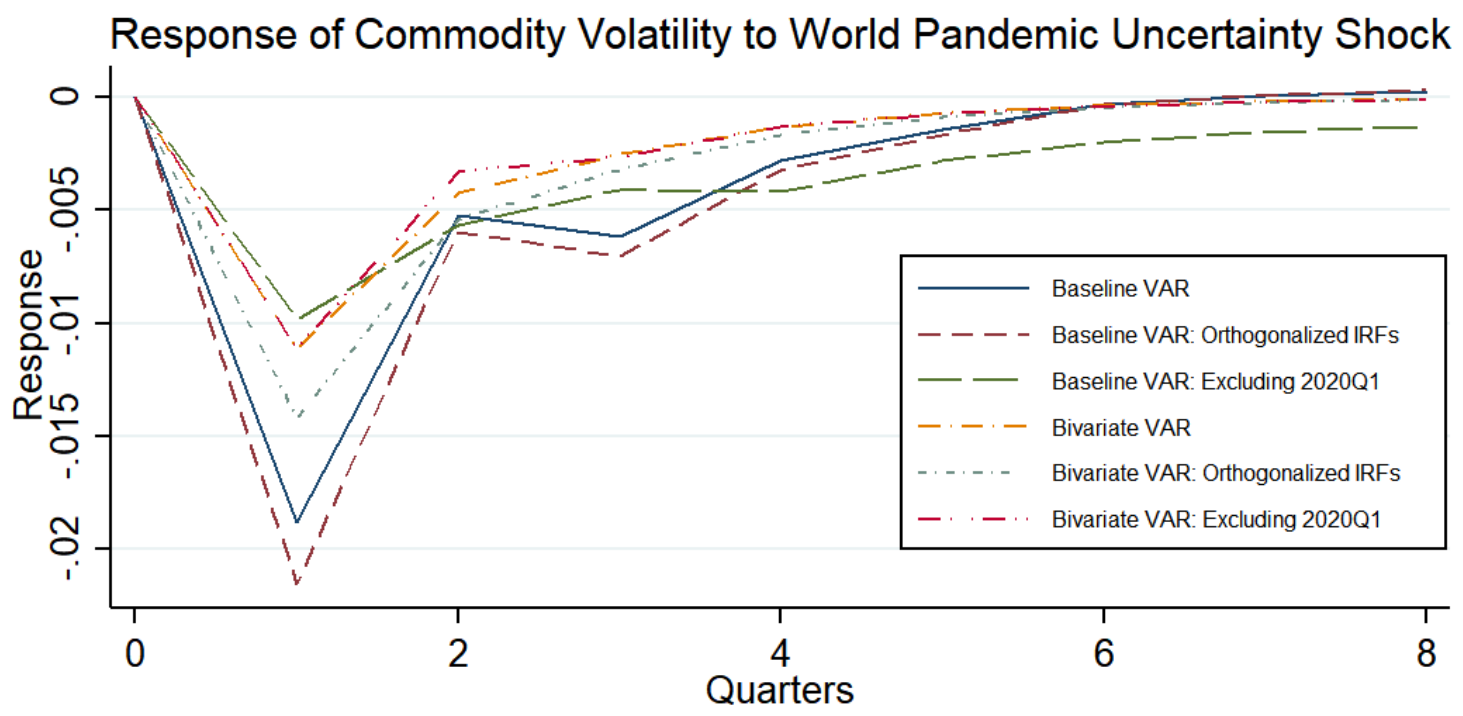


Figure 7. World Pandemic Uncertainty Shock and Crude Oil Volatility (Alternative VARs)

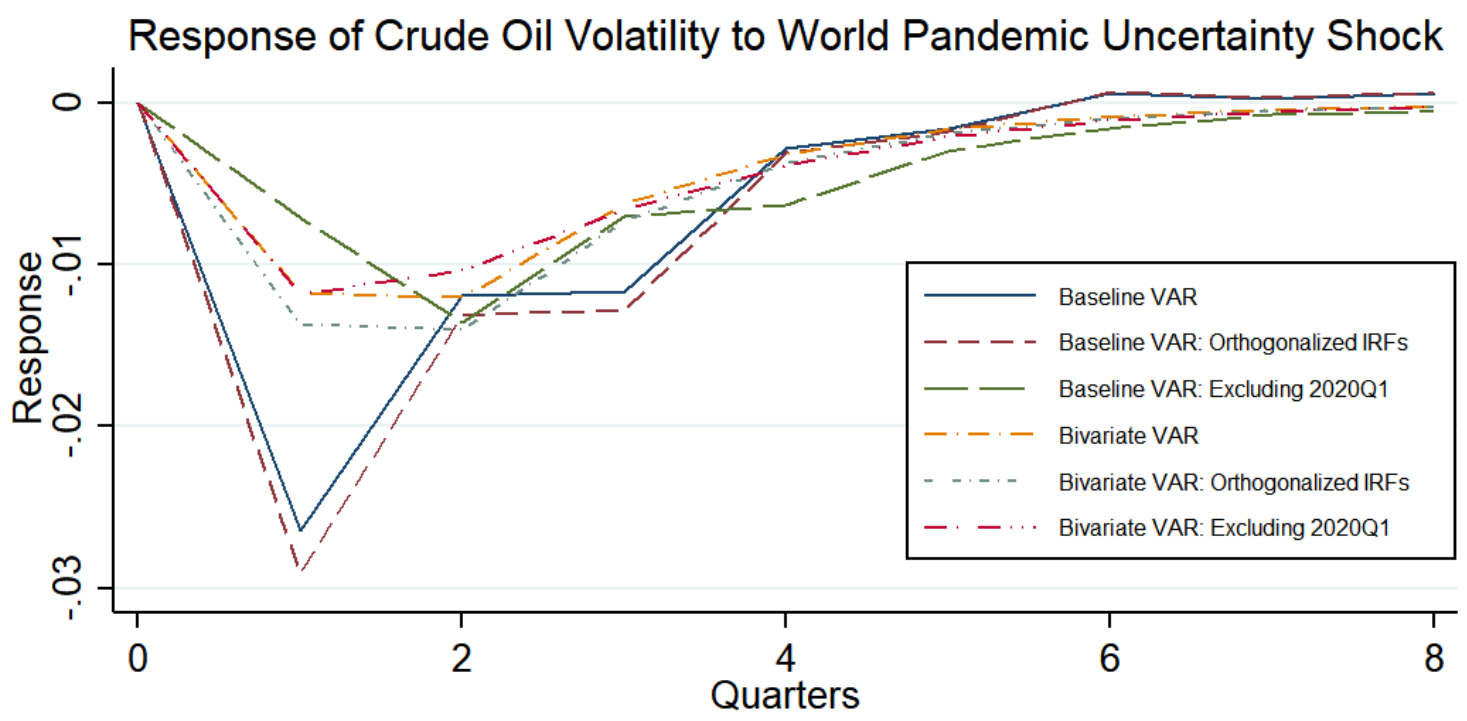

Figure 8. World Pandemic Uncertainty Shock and Gold Volatility (Alternative VARs)

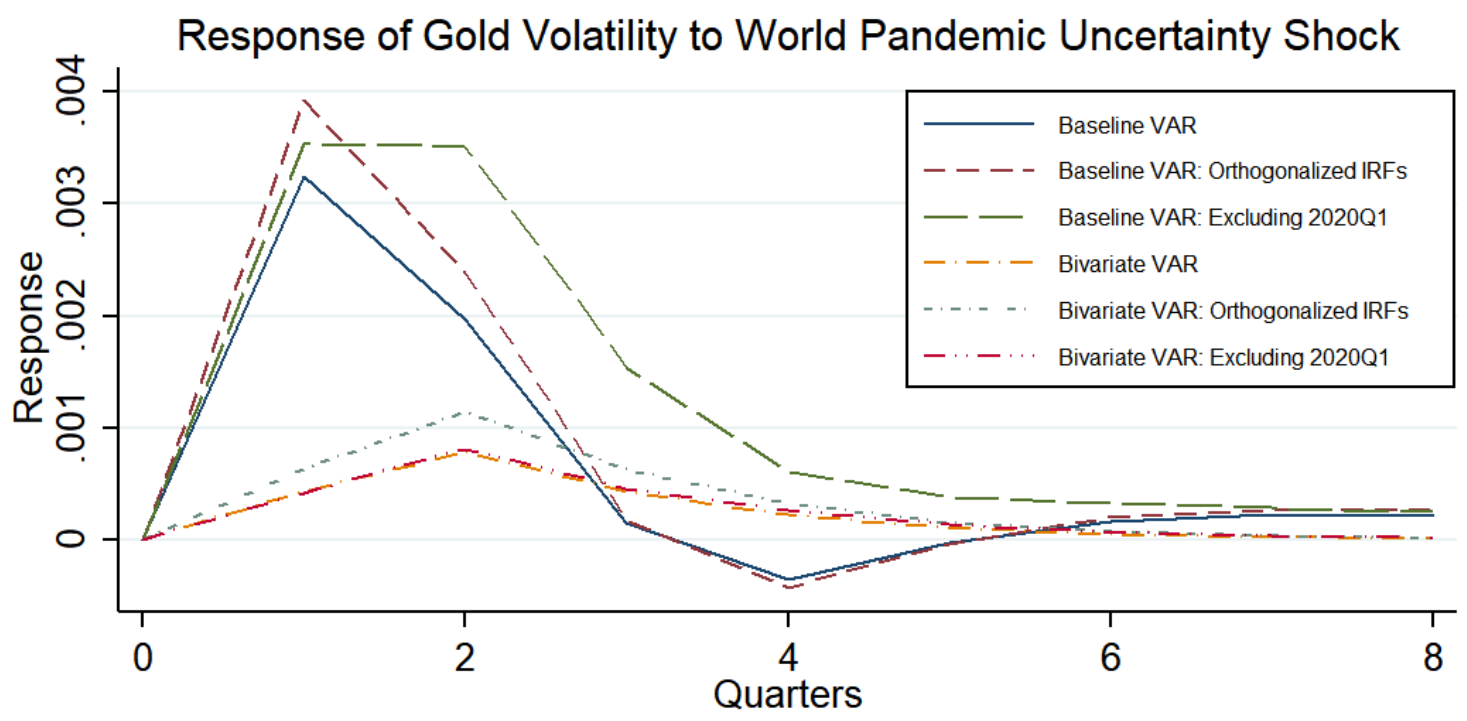

